\title{
Effects of Ginseng on Neurological Disorders
}

\author{
Wei Hou ${ }^{1}$, Yingping Wang ${ }^{1}$, Peihe Zheng ${ }^{1}$ and Ranji Cui ${ }^{2 *}$ \\ ${ }^{1}$ Institute of Special Animal and Plant Sciences, Chinese Academy of Agricultural Sciences, Changchun, China, ${ }^{2}$ Jilin \\ Provincial Key Laboratory on Molecular and Chemical Genetic, The Second Hospital of Jilin University, Changchun, China
}

Ginseng (Panax ginseng Meyer), a famous traditional medicinal herb, has been widely used for many centuries. Numerous studies have shown that ginseng has a positive effect on the prevention and treatment of neurological disorders. In this review, we summarized the effects of ginseng in treating neurological diseases, particularly the anti-depressant effects of ginseng. Furthermore, its potential mechanism was also outlined. Therefore, this review may provide new insight into the treatment of ginseng on neurological diseases.

Keywords: ginseng, neurological disorder, BDNF, depression, neuron

\section{INTRODUCTION}

OPEN ACCESS

Edited by:

Bin Song,

McLean Hospital, United States

Reviewed by:

Sergio Machado,

Salgado de Oliveira University, Brazil

Chengqi $X u$,

Huazhong University of Science and

Technology, China

*Correspondence:

Ranji Cui

cuiranji@jlu.edu.cn

Specialty section:

This article was submitted to

Cellular Neurophysiology,

a section of the journa

Frontiers in Cellular Neuroscience

Received: 05 November 2019

Accepted: 27 February 2020

Published: 20 March 2020

Citation:

Hou W, Wang Y, Zheng P and Cui R (2020) Effects of Ginseng on

Neurological Disorders.

Front. Cell. Neurosci. 14:55.

doi: 10.3389/fncel.2020.00055
In recent years, medicinal plants have received extensive attention in the development of disease treatment. Ginseng (Panax ginseng Meyer, Araliaceous) is a famous traditional medicinal herb that has been used for many centuries. It is mainly distributed in Asian countries including China, Korea, and Japan (Shahrajabian et al., 2019). Ginseng is generally processed into fresh ginseng, red ginseng and white ginseng, according to the different technology (Majid, 2019). Numerous studies indicated ginseng promotes health and prevents potential disease (Rajabian et al., 2019), such as immune-modulatory, anti-inflammatory, lipid-lowering, anti-oxidation, anti-diabetic, anti-tumor, increase energy, restorative, anti-aging, anti-depression, inhibit or delay the neurodegenerative process, improving memory and perceptual systems (Ong et al., 2015). Due to lots of pharmacological effects, ginseng has attracted much attention world widely.

As our global population ages, hundreds of thousands of older adults suffer neurological disorders disease. Most medication has side effects for central nervous system diseases (Dording and Boyden, 2019). However, ginseng as a medicinal plant has fewer side effects in treating diseases, and it has certain advantages in treating central nervous system disease (Shahrajabian et al., 2019). Scholars had reported that red ginseng inhibited neuronal damage and ginseng inhibited or delayed Parkinson's disease (PD), Huntington's disease (HD), and Alzheimer's disease (AD) (Cho, 2012; Iqbal et al., 2019). In addition, the antidepressant activity of ginseng and its ginsenosides has been widely reported. In order to better study and apply ginseng in central nervous system diseases, we describe the neuropharmacology of ginseng in this paper (Table $\mathbf{1}$ ).

\section{ACTIVE CONSTITUENTS}

Various constituents of ginseng possess pharmacological activity including ginsenosides, ginseng polysaccharides, ginseng polypeptides, volatile oils, polyacetylenes, organic acids, and esters (Jin et al., 2019). In all active constituents, ginsenosides are the most pharmacologically active constituents and they are the main focus of ginseng research. Usually, ginsenosides are grouped into two major groups based on their chemical structures, protopanaxadiol (PPD) and protopanaxatriol 
(PPT). The PPD group includes Rb1, Rb2, Rc, Rd, Rg3, Rh2, and Rh3; The PPT group includes Re, Rf, Rg1, Rg2, and Rh1 (Rajabian et al., 2019).

\section{THE TREATMENT OF GINSENG IN NEUROLOGICAL DISORDERS}

\section{The Role of Ginseng on Depression}

Depression is characterized by sleep disturbance, loss of interest, lack of energy, anxiety, and suicidal thoughts (Zhang et al., 2019). Treatments for depression include electroshock therapy, drug therapy, and psychotherapy. However, for major depression disorder, medication is essential. Existing antidepressants like these NA reuptake inhibitors (NRIs) and selective serotonin reuptake inhibitors (SSRIs) possess latency period of antidepressant efficacy (Farber and Goldberg, 2004; Aleksandrova et al., 2019) and three major classical antidepressants possess side effects (Gillman, 2007; Wang et al., 2017). Moreover, currently available ADs are not effective enough (Haenisch and Bonisch, 2011) and mental health resources are not sufficient (Smith, 2014). Therefore, it is necessary to find antidepressants with quicker effects and fewer side effects. The history of ginseng used to treat central nervous system diseases can be traced back to the Eastern Han Dynasty (Wang et al., 2017). In addition, many components of ginseng exert antidepressant effects by acting on different targets.

Impairment of synaptic plasticity was one of the pathogenesis of depression. Synaptic regulators, such as BDNF is important in the treatment of depression (Castren and Rantamaki, 2010). The hippocampus and prefrontal cortex are brain regions associated with depression. Stress and depression reduce the expression and function of BDNF in these two sites. The level of BDNF in the blood of depressed patients is also reduced (Krishnan and Nestler, 2008; Bocchio-Chiavetto et al., 2010). Antidepressants can increase the expression of BDNF (Molteni et al., 2006; Reus et al., 2013; Duman et al., 2016). Ginsenoside Rg5 restored the chronic social defeat stress (CSDS)-induced decrease in hippocampal BDNF signaling cascade (Xu et al., 2017). Ginsenoside Rg3 improved depression-like behavior in the depression model test. Rg3 also reverse the CSDS-induced decrease of BDNF signaling pathway in the brain (You et al., 2017). A possible cause of ethanol-induced depression is a reduction in BDNF levels in the brain. G115 significantly

Abbreviations: BDNF, brain-derived neurotrophic factor; CSDS, chronic social defeat stress; TrkB, Tyrosine Kinase receptor B; ERK, extracellular regulated protein kinases; CREB, cAMP-response element-binding protein; PI3K/Akt, (phosphatidylinositol-3-kinases)/(protein-serine-threonine kinase); 5-HT, 5-hydroxytryptamine; EC, enterochromaffin; DS, dammarane; 5HTP, 5-hydroxytryptophan; HPA, hypothalamic-pituitary-adrenal axis; GR, glucocorticoid receptors; TMT, trimethyltin sapogenins; ROS, reactive oxygen species; NOX2, NADPH oxidase 2; Nrf2, NF-E2-related factor 2; MCAO, middle cerebral artery occlusion; GAP-43, growth associated protein-43; MAPK, mitogenactivated protein kinase; AchE, acetylcholinesterase; nuclear factor kappa-B; $A \beta$, amyloid $\beta$-protein; TLRs, toll-like receptors; JNK, c-Jun N-terminal kinase; MPTP, 1-methyl-4-phenyl-1,2,3,6-tetrahydropyridine; Wnt, wingless; RAGE, receptor for advanced glycation endproducts; AD, Alzheimer's disease; HD, Huntington's disease; PD, Parkinson's disease; OGD, oxygen glucose deprivation; VEGF, vascular endothelial growth factor; CSDS, chronic social defeat stress. increased BDNF levels in the hippocampus and prefrontal cortex of ethanol-induced depression mice (Boonlert et al., 2017). The antidepressant effect of Rg1 and Ginseng sesquiterpenoids may be related to the enhancement of the BDNF-TrkB signaling pathway (Jiang et al., 2012; Wang et al., 2018). Rg1 increases the hippocampal BDNF level and phosphorylation of downstream molecules ERK and CREB in the chronic mild stress mouse model. In addition, the antidepressant effect of $\mathrm{Rg} 1$ can be blocked by the BDNF receptor trkB inhibitor K252a (Jiang et al., 2012). These results suggest that the active ingredient of ginseng may exert antidepressant effects through enhanced BDNF-TrkB signaling pathways (Figure 1).

Serotonin or 5-hydroxytryptamine (5-HT), known as Monoamine neurotransmitters. The decrease in blood serotonin levels is closely related to the occurrence of depression (Sekiyama et al., 2013; Zahn et al., 2015). Ginsenoside Rb1 and compound $\mathrm{K}$ showed an antidepressant-like effect after the ovariectomy during the forced swimming test. $5-\mathrm{HT}_{2 \mathrm{~A}}$ receptors mediated the antidepressant-like effect of Rb1 (Yamada et al., 2011). White ginseng and Ginseng fruit saponin increased 5-HT concentration and improved the depression-like behavior of mice (Jang et al., 2019; Liu M. et al., 2019). High doses of 5-HTP, a precursor of serotonin, can cause head-twitches in mice, and antidepressants that increase serotonin can aggravate this symptom. Similarly, Ginsenoside Rbl can significantly increase the number of head-twitches caused by 5-HTP and Tryptophan hydroxylase inhibitors prevent the antidepressant effects of ginsenosides Rb1. So, ginsenoside Rb1 may have an effect of increasing 5-HT (Wang et al., 2017). Most blood serotonin is supplied by gastrointestinal enterochromaffin (EC) cells and stored in EC cells (McLean et al., 2007; Bertrand and Bertrand, 2010). Intestine-derived serotonin acts in the brain through the gut-brain axis and plays an important role in diseases associated with serotonin, including depression (Saldanha et al., 2009; Albert et al., 2012). Gintonin (intragastric administration) stimulates the release of serotonin from mouse EC cells via lysophosphatidic acid (LPA) receptor-mediated $\left[\mathrm{Ca}^{2+}\right] \mathrm{i}$ transients, followed by elevated plasma serotonin levels, reducing depression-like behavior (Kim et al., 2017). Compared with ginsenosides, dammarane sapogenins (DS), the hydrolysate of ginsenosides, is more easily absorbed by the body and possess stronger biological activity. DS showed significant antidepressant effects in different depression models and significantly increased hippocampal serotonin levels (Jiang et al., 2018). In conclusion, the increase in serotonin levels may be another mechanism by which ginseng active ingredients exert antidepressant effects.

The hyperactivity of the hypothalamic-pituitary-adrenal (HPA) axis caused by stress is related to the pathogenesis of depression (Kawabata et al., 2010), accompanied by the dysfunction of hypothalamic-pituitary-gonadal (HPG) axis (Mou et al., 2017). HPG axis was weakened in depressed individuals (Jin et al., 2019) and testosterone can improve depression mood in clinical therapy (Kanayama et al., 2007). HPA axis is the biological system responsible for stress response. When stress occurs, the hypothalamic releases the adrenocorticotropic releasing hormone and arginine vasopressin to the pituitary gland to produce the adrenocorticotropic 
TABLE 1 | Effects and mechanisms of active ingredients of ginseng on the central nervous system disease.

\begin{tabular}{|c|c|c|c|c|c|c|}
\hline Effects & Cells/Animals & Dose and route & Model & Active ingredients & Mechanism & References \\
\hline Anti-depression & $\begin{array}{l}\text { Adult male C57BL/6J mice (8-10 weeks } \\
\text { old) and male CD1 mice ( } 50 \text { weeks old) }\end{array}$ & $\begin{array}{l}5,10,20 \text {, and } 40 \mathrm{mg} / \mathrm{kg} \\
\text { (intraperitoneally) }\end{array}$ & Chronic social defeat stress & Rg5 & $\begin{array}{l}\text { Activating hippocampal BDNF } \\
\text { system }\end{array}$ & Xu et al., 2017 \\
\hline Anti-depression & $\begin{array}{l}\text { Adult male C57BL/6J mice ( } 8-10 \text { weeks } \\
\text { old) and male CD1 mice ( } 50 \text { weeks old) }\end{array}$ & $\begin{array}{l}10 \text { and } 20 \mathrm{mg} / \mathrm{kg} \\
\text { (intraperitoneally) }\end{array}$ & Chronic social defeat stress & Rg3 & $\begin{array}{l}\text { Activating hippocampal BDNF } \\
\text { system }\end{array}$ & You et al., 2017 \\
\hline Anti-depression & $\begin{array}{l}\text { Weighing } 20-25 \mathrm{~g} \text { (National Laboratory } \\
\text { Animal Center, Mahidol University) }\end{array}$ & $\begin{array}{l}\text { 10, 20, 40, and } 80 \mathrm{mg} / \mathrm{kg} \mathrm{G} 115 \\
\text { (oral gavage) }\end{array}$ & Ethanol-treated & G115 & $\begin{array}{l}\text { Increasing BDNF levels in the } \\
\text { hippocampus and prefrontal } \\
\text { cortex }\end{array}$ & Boonlert et al., 2017 \\
\hline Anti-depression & $\begin{array}{l}\text { Adult male C57BL/6J mice (8-10 weeks } \\
\text { old) }\end{array}$ & $\begin{array}{l}2.5,5,10 \text {, and } 20 \mathrm{mg} \cdot \mathrm{kg}^{-1} \\
\text { (intraperitoneally) }\end{array}$ & Chronic mild stress & Rg1 & $\begin{array}{l}\text { Activating BDNF signaling } \\
\text { pathway and up-regulation of } \\
\text { hippocampal neurogenesis } \\
\text { BDNF-TrkB }\end{array}$ & Jiang et al., 2012 \\
\hline Anti-depression & Male ICR mice (18-22 g) & 0.25 and $1 \mathrm{mg} / \mathrm{kg}$ (oral gavage) & $\begin{array}{l}\text { Lipopolysaccharide-induced } \\
\text { depression }\end{array}$ & Ginseng sesquiterpenoids & $\begin{array}{l}\text { Modulating BDNF/TrkB and } \\
\text { Sirt1/NF-kB signaling pathways. }\end{array}$ & Wang et al., 2018 \\
\hline Anti-depression & ICR albino female mice & $\begin{array}{l}\mathrm{Rb} 12.5,5 \text {, and } 10 \mathrm{mg} / \mathrm{kg} / \text { day; } \\
\text { compound } \mathrm{K} 1.25,2.5,5 \\
\mathrm{mg} / \mathrm{kg} / \text { day (intraperitoneally) }\end{array}$ & Ovariectomy & Rb1, compound K & Modulating 5- $\mathrm{HT}(2 \mathrm{~A})$ receptors & Yamada et al., 2011 \\
\hline \multirow[t]{2}{*}{ Anti-depression } & $\begin{array}{l}\text { Female Sprague Dawley rats aged } 10 \\
\text { weeks (body weight: } 180-200 \mathrm{~g} \text { ) }\end{array}$ & 200 and $400 \mathrm{mg} / \mathrm{kg}$ per os & $\begin{array}{l}\text { Ovariectomized and restraint } \\
\text { stressed }\end{array}$ & White ginseng powder & $\begin{array}{l}\text { Increasing hippocampal 5-HT } \\
\text { level }\end{array}$ & Jang et al., 2019 \\
\hline & $\begin{array}{l}\text { Male ICR mice }(22-24 \mathrm{~g}) \text { and Wistar rats } \\
(200-220)\end{array}$ & 4,8 , and $10 \mathrm{mg} / \mathrm{kg}$ per os & Chronic unpredicted mild stress & ginsenoside Rb1 & $\begin{array}{l}\text { Modulating serotonergic, } \\
\text { noradrenergic and dopaminergic } \\
\text { systems. }\end{array}$ & Wang et al., 2017 \\
\hline Anti-depression & Male C57BL/6 J mice weighing 20-25 g & 20 mg/kg/d (intragastric gavage) & $\begin{array}{l}\text { Sucrose Preference Test } \\
\text { Tail Suspension Tests } \\
\text { Forced Swim Tests }\end{array}$ & Ginseng fruit saponin & Regulating 5-HT concentrations & Liu L. et al., 2019 \\
\hline Anti-depression & $\begin{array}{l}\text { Adult Kunming mice (male) and } \\
\text { Sprague-Dawley rats (male) }\end{array}$ & $\begin{array}{l}5,10,20 \text {, and } 40 \mathrm{mg} \cdot \mathrm{kg}^{-1} \\
\text { (intragastric gavage) }\end{array}$ & $\begin{array}{l}\text { Chronic-unpredictable-mild- } \\
\text { stress } \\
\text { Gonadectomized model }\end{array}$ & Rg1 & $\begin{array}{l}\text { Modulating HPA and the HPG } \\
\text { axis }\end{array}$ & Mou et al., 2017 \\
\hline Anti-depression & BALB/c male mice $20-22 \mathrm{~g}$ & $\begin{array}{l}20,40 \text {, and } 80 \mathrm{mg} / \mathrm{kg} \\
\text { (intragastric gavage) }\end{array}$ & $\begin{array}{l}\text { Chronic unpredictable mild } \\
\text { stress }\end{array}$ & dammarane sapogenins & $\begin{array}{l}\text { Regulating neurotransmitters and } \\
\text { hypothalamic-pituitary-adrenal } \\
\text { axis }\end{array}$ & Jiang et al., 2018 \\
\hline Anti-depression & $\begin{array}{l}\text { Adult male C57BL/6 mice 8-10 week of } \\
\text { age }\end{array}$ & $\begin{array}{l}75,150 \text {, and } 300 \mathrm{mg} / \mathrm{kg} \\
\text { (intragastric gavage) }\end{array}$ & Chronic restraint stress & $\begin{array}{l}\text { Panax ginseng aqueous } \\
\text { extract }\end{array}$ & $\begin{array}{l}\text { Inhibiting } \\
\text { hypothalamo-pituitary-adrenal } \\
\text { axis }\end{array}$ & Choi et al., 2018 \\
\hline Anti-depression & $\begin{array}{l}\text { Human neuroblastoma SHSY-5Y cells } \\
\text { (passages 20-30) }\end{array}$ & $\begin{array}{l}\mathrm{Rb} 1100 \mathrm{ng} / \mathrm{ml} \\
\mathrm{Rg} 3100 \mathrm{ng} / \mathrm{ml}\end{array}$ & & Rb1 and Rg3 & Glucocorticoid & Kim et al., 2010 \\
\hline Neuroprotection & $\begin{array}{l}\text { The wildtype and the } \mathrm{Nrf}^{-/-} \text {mice had a } \\
\text { C57BL/6 genetic background (10-18 } \\
\text { weeks old) }\end{array}$ & 100 mg/kg/day(gavage) & $\begin{array}{l}\text { Permanent distal middle cerebral } \\
\text { artery occlusion }\end{array}$ & $\begin{array}{l}\text { The standardized Korean } \\
\text { red ginseng, a water-soluble } \\
\text { extract }\end{array}$ & Nrf2-dependent & Liu L. et al., 2019 \\
\hline Neuroprotection & $\begin{array}{l}\text { Young ( } 4 \text { months), middle-aged ( } 12 \\
\text { months) and aged mice ( } 24 \text { months) with a } \\
\text { C57BL/6J background }\end{array}$ & $0.5,1,5$, and $10 \mathrm{mg} / \mathrm{kg}$ (gavage) & Middle cerebral artery occlusion & Rb1 & Anti-Oxidant Signaling & Dong et al., 2017 \\
\hline
\end{tabular}




\begin{tabular}{|c|c|c|c|c|c|c|}
\hline Effects & Cells/Animals & Dose and route & Model & Active ingredients & Mechanism & References \\
\hline Neuroprotection & Male ICR mice, weighing 25-30 g & $\begin{array}{l}5,20, \text { or } 40 \mathrm{mg} / \mathrm{kg} \\
\text { (intraperitoneal injection) }\end{array}$ & Middle cerebral artery occlusion & ginsenoside Rb1 & $\begin{array}{l}\text { Suppressing neuroinflammation } \\
\text { induction of MMP-9 and } \\
\text { NOX4-derived free radicals }\end{array}$ & Chen et al., 2015 \\
\hline Neuroprotection & $\begin{array}{l}\text { Male Sprague-Dawley rats weigh } \\
270-320 \mathrm{~g}\end{array}$ & 30 mg/kg (intraperitoneally) & Middle cerebral artery occlusion & $\mathrm{Rd}$ & $\begin{array}{l}\text { Up-regulating GLT-1 expression } \\
\text { through PI3K/AKT and ERK1/2 }\end{array}$ & Zhang et al., 2013 \\
\hline Neuroprotection & PC12 cells & $0.1-100 \mu \mathrm{M}$ & & Ginsenoside Rd & $\begin{array}{l}\text { Promoting the neurite outgrowth } \\
\text { via ERK and AKT dependent } \\
\text { signaling pathways }\end{array}$ & Wu et al., 2016 \\
\hline Neuroprotection & $\begin{array}{l}\text { Male SD rats } \\
\text { PC12 cells }\end{array}$ & $\begin{array}{l}1,2.5 \text {, and } 5 \mathrm{mg} \cdot \mathrm{kg}^{(-1)} \cdot \mathrm{d}^{(-1)} \\
\text { (intraperitoneally) } \\
25,50 \text {, and } 100 \mu \mathrm{mol} / \mathrm{L}\end{array}$ & $\begin{array}{l}\text { Transient middle cerebral artery } \\
\text { occlusion } \\
\text { Oxygen glucose deprivation }\end{array}$ & ginsenoside Rd & $\begin{array}{l}\text { Activating the PI3K/Akt and } \\
\text { ERK } 1 / 2\end{array}$ & Liu X. Y. et al., 2015 \\
\hline Neuroprotection & $\begin{array}{l}\text { Male BALB/c mice }(25-30 \mathrm{~g}) \\
\text { Mice astrocytes }\end{array}$ & $\begin{array}{l}20 \text { and } 40 \mathrm{mg} / \mathrm{kg} \\
\text { (intraperitoneally) } \\
0,2.5,5,10 \text {, and } 20 \mu \mathrm{M}\end{array}$ & $\begin{array}{l}\text { Transient middle cerebral artery } \\
\text { occlusion } \\
\mathrm{H}_{2} \mathrm{O}_{2} \text {-induced apoptosis }\end{array}$ & Rg1 & $\begin{array}{l}\text { Preventing the astrocytes from } \\
\text { apoptosis. }\end{array}$ & Sun et al., 2014 \\
\hline Neuroprotection & $\begin{array}{l}\text { Male Wistar rats aged } 45-60 \mathrm{~d} \text { old and } \\
\text { body weights from } 250 \text { to } 300 \mathrm{~g}\end{array}$ & $25 \mathrm{mg}^{(-1)} \cdot \mathrm{d}^{(1)}$ (intraperitoneally) & Middle cerebral artery occlusion & Ginseng total saponins & Protecting brain cell & Zheng et al., 2011 \\
\hline Neuroprotection & $\begin{array}{l}\text { Immortalized murine BV2 microglial cells, } \\
\text { C57BL/6 mice 10-11 weeks old }\end{array}$ & $\begin{array}{l}\text { Compound } \mathrm{K}(25,50 \text {, and } \\
75 \mu \mathrm{M}), 30 \mathrm{mg} / \mathrm{kg} \\
\text { (intraperitoneally) }\end{array}$ & $\begin{array}{l}\text { Systemic inflammation } \\
\text { Middle Cerebral Artery Occlusion }\end{array}$ & Compound K & Inhibiting activation of microglial & Park et al., 2012 \\
\hline Neuroprotection & $\begin{array}{l}\text { Male Sprague-Dawley rats weighing } \\
\text { between } 250 \text { and } 300 \mathrm{~g}\end{array}$ & $20 \mathrm{mg} / \mathrm{kg}$ & $\begin{array}{l}\text { Subarachnoid } \\
\text { hemorrhage-induced brain injury }\end{array}$ & Rb1 & $\begin{array}{l}\text { Reducing arterial vasospasm } \\
\text { and brain edema }\end{array}$ & Li et al., 2011 \\
\hline $\begin{array}{l}\text { Improve } \\
\text { cognition }\end{array}$ & Male C57BL/6 mice (10 weeks, 25-27 g) & 50 and 100 mg/kg (oral gavage) & $\begin{array}{l}\text { Scopolamine-induced memory } \\
\text { deficits }\end{array}$ & $\begin{array}{l}\text { ginsenoside Rg3-enriched } \\
\text { ginseng ethanol extract }\end{array}$ & $\begin{array}{l}\text { Inhibiting of acetylcholinesterase } \\
\text { activity and NF-kB signaling }\end{array}$ & Kim J. et al., 2016 \\
\hline $\begin{array}{l}\text { Improve } \\
\text { cognition }\end{array}$ & Male ICR mice (28-30 g) & $\begin{array}{l}5,10 \text {, and } 20 \mathrm{mg} / \mathrm{kg} \text { (oral } \\
\text { gavage) }\end{array}$ & $\begin{array}{l}\text { Scopolamine-induced memory } \\
\text { deficits }\end{array}$ & Rh3 and Rg5 & $\begin{array}{l}\text { Inhibiting AChE activity and } \\
\text { increasing BDNF expression and } \\
\text { CREB activation }\end{array}$ & Kim et al., 2013 \\
\hline $\begin{array}{l}\text { Improve } \\
\text { cognition }\end{array}$ & Male ICR mice, 6 months of age & 5 and $10 \mathrm{mg} / \mathrm{kg} /$ day(oral gavage) & & Rh1 & $\begin{array}{l}\text { Enhancing cell survival and } \\
\text { expression of BDNF }\end{array}$ & Hou et al., 2014 \\
\hline $\begin{array}{l}\text { Improve } \\
\text { cognition }\end{array}$ & Male C57BL/6J mice (12-month-old) & $\begin{array}{l}0.1,1 \text {, and } 10 \mathrm{mg} / \mathrm{kg} \\
\text { (intraperitoneally) }\end{array}$ & & Rg1 & $\begin{array}{l}\text { Regulating the PI3K/AKT } \\
\text { pathway, altering apical spines } \\
\text { and facilitating hippocampal LTP }\end{array}$ & Zhu et al., 2015 \\
\hline Anti-AD & $\begin{array}{l}\text { The mouse hippocampal neuronal HT22 } \\
\text { cell line } \\
\text { The littermates obtained through the } \\
\text { crossing of male 5XFAD mice and female } \\
\text { B6SJL/F1 mice }\end{array}$ & $\begin{array}{l}1,10 \text {, and } 100 \mu \mathrm{g} / \mathrm{mL} \\
100 \mathrm{mg} / \mathrm{kg} \text { (oral gavage) }\end{array}$ & $\begin{array}{l}\text { Amyloid beta-mediated } \\
\text { mitochondrial dysfunction }\end{array}$ & red ginseng $\mathrm{MeOH}$ extract & Mitochondria-related & Shin et al., 2019 \\
\hline Anti-AD & PC12 cells & $\begin{array}{l}\beta \text {-sitosterol, and stigmasterol } 0.1 \\
\text { and } 1.10 \mu \mathrm{M} \\
\text { Linoleic acid } 10,50 \text {, and } 100 \mu \mathrm{M}\end{array}$ & $A \beta_{25-35}$ treatment & $\begin{array}{l}\text { linoleic acid, } \beta \text {-sitosterol, } \\
\text { and stigmasterol }\end{array}$ & $\begin{array}{l}\text { Regulating oxidative stress, } \\
\text { apoptotic responses, and } \\
\text { pro-inflammatory mediators }\end{array}$ & Lee et al., 2018b \\
\hline Anti-AD & $\begin{array}{l}\text { Male Wistar rats } 400 \pm 50 \mathrm{~g} \text {, human } \\
\text { neuroblastoma SH-SY5Y cells }\end{array}$ & $\begin{array}{l}40,80 \text {, and } 160 \mathrm{mg} / \mathrm{kg} \cdot \mathrm{d}^{-1} \\
\text { intraperitoneally } \\
0.03,0.1,0.3 \text {, or } 1 \mu \mathrm{g} / \mathrm{mL}\end{array}$ & $A \beta_{25-35}$ treatment & PGL-1 & $\begin{array}{l}\text { Reducting NO concentration and } \\
\text { NOS activity }\end{array}$ & Luo et al., 2018 \\
\hline
\end{tabular}


TABLE 1 | Continued

\begin{tabular}{|c|c|c|c|c|c|c|}
\hline Effects & Cells/Animals & Dose and route & Model & Active ingredients & Mechanism & References \\
\hline Anti-AD & $\begin{array}{l}\text { Sprague-Dawley (SD) embryo rat cortical } \\
\text { neurons }\end{array}$ & $5,10,20$, and $40 \mu \mathrm{mol}$ & $A \beta_{25-35}$ treatment & $\mathrm{Rb} 1$ & $\begin{array}{l}\text { Attenuating expression of } \\
\text { JNK/p38 MAPK }\end{array}$ & Song et al., 2008 \\
\hline Anti-AD & $\begin{array}{l}\text { APP transgenic mice, at the age of } 10 \\
\text { months }\end{array}$ & 10 mg/kg (intraperitoneally) & & $\mathrm{Rd}$ & $\begin{array}{l}\text { Inhibiting the transcription activity } \\
\text { of } \mathrm{NF}_{\mathrm{KB}}\end{array}$ & Liu J. et al., 2015 \\
\hline Anti-AD & Neuroglial cell line NG108-15 & $2,4,8,16$, and $32 \mu \mathrm{g} / \mathrm{mL}$ & $A \beta_{25-35}$ treatment & Rg1 & $\begin{array}{l}\text { Suppressing the signaling } \\
\text { transduction pathway of TLR3 } \\
\text { and TLR4, inflammation factors }\end{array}$ & Zhao et al., 2014 \\
\hline Anti-AD & $\begin{array}{l}\text { Hippocampal neurons from the } \\
\text { Sprague-Dawley neonates }\end{array}$ & $50 \mu \mathrm{M}$ & $A \beta_{25-35}$ treatment & Rg1 & $\begin{array}{l}\text { Activating Akt and ERK1/2 } \\
\text { signaling }\end{array}$ & Huang et al., 2016 \\
\hline Anti-AD & $\begin{array}{l}\text { Male Wistar rats weighing } 180-220 \mathrm{~g} \\
\text { (aged } 7 \text { weeks) }\end{array}$ & $2 \mathrm{~g} / \mathrm{kg} /$ day (oral gavage) & d-galactose and $\mathrm{AICl} 3$ treatment & $\begin{array}{l}\text { total ginsenosides water } \\
\text { extracted }\end{array}$ & $\begin{array}{l}\text { Restoring the dysfunction of } \\
\text { various neurotransmitters }\end{array}$ & Zhang Y. et al., 2016 \\
\hline Anti-AD & $\begin{array}{l}\text { Adult male Sprague-Dawley rats } \\
(280-300 \mathrm{~g})\end{array}$ & $\begin{array}{l}1,0.5 \text {, and } 0.25 \mathrm{~g} / \mathrm{kg} \text { (oral } \\
\text { gavage) }\end{array}$ & $\begin{array}{l}\text { Advanced glycation end product } \\
\text { treatment }\end{array}$ & Ginseng water extracts & RAGE/NF-kB & Tan et al., 2015 \\
\hline Anti-PD & $\begin{array}{l}\text { The dopaminergic cell of OF1/SPF } \\
\text { embryos mice }\end{array}$ & $\begin{array}{l}\text { Rd } 1-10 \mu \mathrm{M} \\
\operatorname{Re} 1-10 \mu \mathrm{M}\end{array}$ & $\mathrm{CCl} 4$ treatment & $\mathrm{Rd}$ and $\mathrm{Re}$ & $\begin{array}{l}\text { Inhibiting oxidative stress and } \\
\text { inflammation }\end{array}$ & Zhang X. et al., 2016 \\
\hline Anti-PD & $\begin{array}{l}\text { SH-SY5Y cells } \\
\text { Adult male C57BL/6J mice }(22-25 \mathrm{~g})\end{array}$ & $\begin{array}{l}1 \text { and } 10 \mu \mathrm{M} \\
10 \mathrm{mg} / \mathrm{kg} \text { (intraperitoneally) }\end{array}$ & $\begin{array}{l}\text { 1-methyl-4-phenylpyridinium } \\
\text { treatment } \\
\text { 1-methyl-4-phenyl-1,2,3,6- } \\
\text { tetrahydropyridine treatment }\end{array}$ & Ginsenoside Rd & $\begin{array}{l}\text { Antioxidant effects and } \\
\text { mitochondrial function } \\
\text { preservation }\end{array}$ & Liu Y. et al., 2015 \\
\hline Anti-PD & $\begin{array}{l}\text { C57BL/6J mice (6-8 weeks old, male, } \\
\text { weighing 16-25 g) } \\
\text { Rat pheochromocytoma PC12 cells }\end{array}$ & $\begin{array}{l}5,10 \text {, and } 20 \mathrm{mg} / \mathrm{kg} \\
\text { (intraperitoneally) } \\
20 \mu \mathrm{M}\end{array}$ & $\begin{array}{l}\text { 1-methyl-4-phenyl-1,2,3,6- } \\
\text { tetrahydropyridine treatment } \\
\text { 1-methyl-4- } \\
\text { phenylpyridinium treatment }\end{array}$ & Rg1 & Wnt/ $/$-catenin & Zhou et al., 2016 \\
\hline Anti-PD & Adult female Wistar rats (250-300 g) & $\begin{array}{l}10 \mathrm{mg} / \mathrm{kg}, 10 \mathrm{mg} / \mathrm{ml} \\
\text { (intraperitoneally) }\end{array}$ & Lipopolysaccharide treatment & Rg1 & $\begin{array}{l}\text { Glucocorticoid receptor signaling } \\
\text { pathway }\end{array}$ & Sun et al., 2016 \\
\hline Anti-PD & Male C57BL/6 mice (9 weeks old) & $100 \mathrm{mg} / \mathrm{kg}$ (oral gavage) & $\begin{array}{l}\text { 1-methyl-4-phenyl-1,2,3,6- } \\
\text { tetrahydropyridine } \\
\text { treatment }\end{array}$ & $\begin{array}{l}\text { Korean Red Ginseng water } \\
\text { extract }\end{array}$ & $\begin{array}{l}\text { Alleviates protein expression } \\
\text { profiles }\end{array}$ & Kim D. et al., 2016 \\
\hline Anti-PD & $\begin{array}{l}\text { Male Wistar rats aged } 3 \text { months and } \\
\text { weighing } 240-280 \mathrm{~g}\end{array}$ & 20 mg/kg (intraperitoneally) & Lipopolysaccharide treatment & Rb1 & $\begin{array}{l}\text { Inhibiting inflammation protecting } \\
\text { dopaminergic neuron }\end{array}$ & Li et al., 2019 \\
\hline Anti-HD & $\begin{array}{l}\text { Male Sprague-Dawley rats weighing } 240 \\
\pm 10 \mathrm{~g}\end{array}$ & $\begin{array}{l}5,10 \text {, and } 20 \mathrm{mg} / \mathrm{kg} \text { (oral } \\
\text { gavage) }\end{array}$ & 3-nitropropionic acid treatment & Protopanaxtriol & Anti-oxidant & Gao et al., 2015 \\
\hline Anti-HD & $\begin{array}{l}\text { Medium spiny striatal neuronal cultures } \\
\text { from the YAC128 HD mouse model }\end{array}$ & $\begin{array}{l}\text { Rb1 } 0.01 \text { and } 0.1 \mu \mathrm{M} \text {; Rc } \\
0.01 \mu \mathrm{M} ; \mathrm{Rg} 51.0 \mu \mathrm{M}\end{array}$ & Glutamate stimulation & $\mathrm{Rg} 5, \mathrm{Rb} 1$ and $\mathrm{Rc}$ & Anti-apoptosis & Wu et al., 2009 \\
\hline
\end{tabular}

MAPK, mitogen-activated protein kinase; ERK, extracellular signal-regulated kinase; TLR, toll-like receptor; RAGEs, the receptors for advanced glycation end products; NF-kB, nuclear factor-kappa-light-chain-enhancer of activated B cell; JNK, c-Jun N-terminal kinase; BDNF, brain-derived neurotrophic factor; TrkB, brain-derived neurotrophic factor; 5-HT, 5-hydroxytryptamine; HPA, hypothalamic-pituitary-adrenal axis; HPG, hypothalamic pituitary gonadal axis; Nif2, NF-E2-related factor 2; MMP-9, matrix metalloproteinase-9; NOX, nicotinamide adenine dinucleotide phosphate oxidase; GLT-1, glutamate transporter 1; PI3K/AKT, (phosphatidylinositol-3-kinases)/(protein-serine-threonine kinase); acetylcholinesterase; LTP, Iong-term potentiation; AChE, acetylcholinesterase; CREB, CAMP-response element-binding protein; AD, Alzheimer's disease; HD, Huntington's disease; PD, Parkinson's disease. 


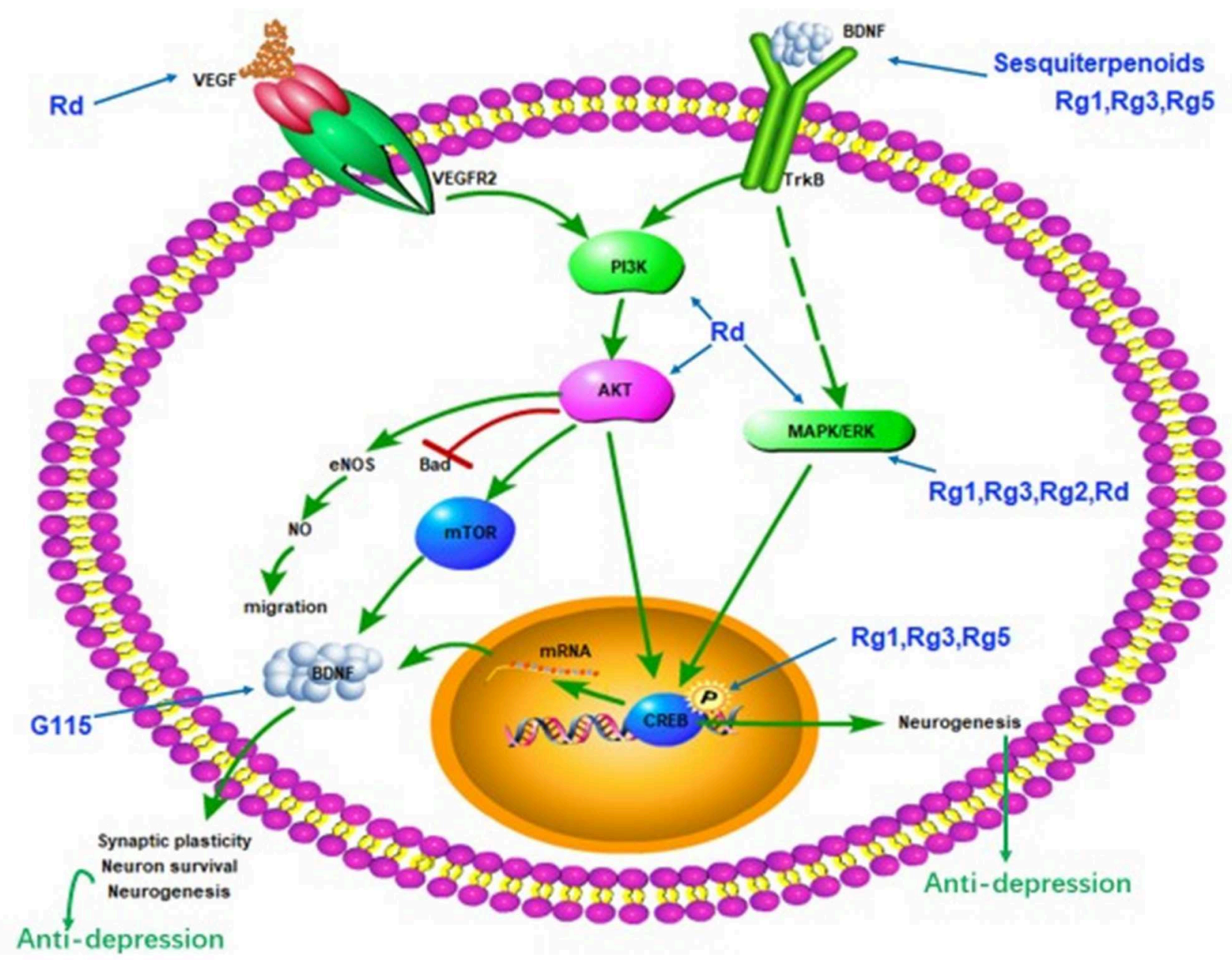

FIGURE 1 | Schematic diagram summarizing the antidepressant effect of ginseng via the BDNF-TrkB signal path. G115, ginseng extract G115; BDNF, brain-derived neurotrophic factor; VEGF, vascular endothelial growth factor; PI3K, phosphoinositide 3-kinase; AKT, protein kinase B; mTOR, mammalian target of rapamycin; MAPK, mitogen-activated protein kinase; ERK, extracellular regulated protein kinases; CREB, cAMP-response element-binding protein.

hormone, which stimulates the adrenal gland to produce cortisol or corticosterone (Lee and Rhee, 2017; Shapero et al., 2019; Figure 2). Cortisol plays an important role in learning, memory, and emotion (Sapolsky et al., 2000). However, excessive cortisol produced by stress can alter the function of the brain associated with depression, like the hippocampus, prefrontal cortex, and the amygdala (McEwen, 2008; Shapero et al., 2019). Rg1 alleviated anhedonia, hopelessness and improved sleep disruption through the modulation levels of corticosterone, testosterone, androgen receptor (AR), and glucocorticoid receptor (GR) in the chronic-unpredictable-mildstress model and the gonadectomized model (Mou et al., 2017). Panax ginseng extract exerted an antidepressant-like effect by inhibiting the HPA axis in depressed mice (Choi et al., 2018). Treatment with DS reverses the rise in corticotropin-releasing factor, adrenocorticotropic hormone, and cortisol in the serum of mice (Jiang et al., 2018). The excessive corticotropin-releasing factor is associated with depression and anxiety (Arborelius et al., 1999). In addition, dexamethasone-induced cytotoxicity was blocked by Rb1 and Rg3 (Kim et al., 2010). Increased glucocorticoid levels as a result of stress can reduce the expression of glucocorticoid receptors (GR), which then block GR-TrkB interaction and BDNF (Chiba et al., 2012). Rh2 and Compound $\mathrm{K}$, as a ligand for GR, can activate GR (Lee and Ji, 2014). Therefore, the active ingredients of ginseng may exert antidepressant effects through the HPA axis.

Inflammatory cytokine disorders may lead to depression. Our previous study elaborated the anti-depression mechanism of ginseng through the immune system and ginsenosides Rg1 exert antidepressant effects through multiple signaling pathways of cells (Jin et al., 2019). It is worth mentioning that ginsenosides Rg1 seems to exert antidepressant effects in a variety of ways (Figures 1, 2). Such as the BDNF-TrkB signaling pathway, HPA axis and immune system. Moreover, Rg1 is the main component of ginseng with a variety of biological activities, such as promoting neurogenesis and neurotrophin expression, 


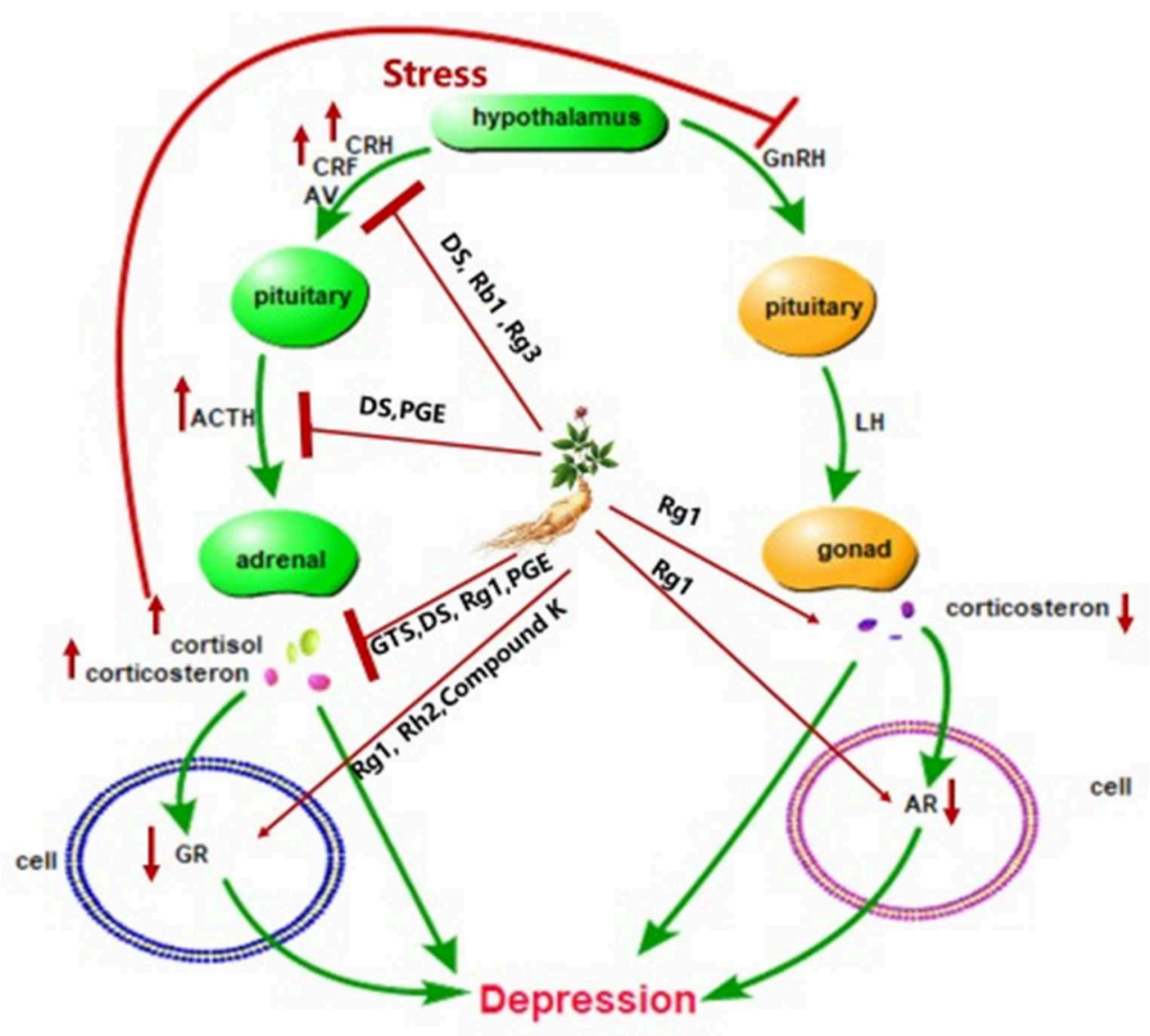

FIGURE 2 | Schematic diagram summarizing the antidepressant effect of ginseng via the HPA axis. CRH, corticotrophin-releasing hormone; AV, arginine vasopressin; ACTH, adrenocorticotropic hormone; CRF, corticotropin-releasing factor; GR, glucocorticoid receptor; AR, androgen receptor; GnRH, gonadotropin-releasing hormone; LH, luteinizing hormone; DS, dammarane sapogenins; PGE, Panax ginseng extract; GTS, ginseng total saponins.

acting on glucocorticoid receptors, and sex hormone receptors (Mou et al., 2017). Therefore, Rg1 may become a new generation of antidepressants.

\section{The Role of Ginseng on Neuronal Damage}

Because of its high oxidative metabolic rate and low antioxidant capacity, the brain is highly susceptible to oxidative stress, leading to neuroinflammation, and damage. Heat stress can trigger oxidative stress and inflammatory factor release, leading to neurogenesis damage, and neuronal death. Red Ginseng (RG) mitigated the release of proinflammatory mediators and neuronal damage induced by heat stress in the rat (Iqbal et al., 2019). Trimethyltin (TMT) was a strong neurotoxin that can induce hippocampal neuronal injury. Rh2 and $\operatorname{Rg} 3$ decreased TMT-induced neurotoxicity and oxidative stress by enhancing PI3K/Akt signaling pathways and inhibiting ERK activation (Hou et al., 2018). Ginsenoside $\mathrm{Rg} 1$ protects against $\mathrm{H}_{2} \mathrm{O}_{2}$ induced neuronal damage. $\mathrm{H}_{2} \mathrm{O}_{2}$ treatment increased reactive oxygen species (ROS) production and induced hippocampal neuron damage. NADPH oxidase 2 (NOX2) mainly produced ROS in the brain. $\operatorname{Rg} 1$ may reduce NOX2-mediated ROS generation and inhibit neuronal damage (Xu et al., 2019). $\mathrm{Rb} 2$ possesses neuroprotective effects by suppressing glutamateinduced neurotoxicity. Glutamate was the prime excitatory neurotransmitter. Excessive glutamate concentration in the brain can cause neurotoxicity (Kim et al., 2019). The degree of the inflammatory response is positively correlated with the degree of brain damage. Rb1 increased Streptococcus pneumoniae clearance and cell survival by increasing the expression of BDNF and antiapoptotic factors (Lee et al., 2018a). In a word, Ginseng may protect neuron from neurotoxicity and other damage

Stroke was a brain rupture or obstruction in the brain's blood supply. It was divided into two types: ischemic stroke and hemorrhagic stroke. Cerebral ischemia is a devastating disease with high mortality and disability primarily due to infarction. Korean Red Ginseng attenuated long-term brain damage and protected neuro in a permanent cerebral ischemia model. The transcriptional factor Nrf2 played an important role in the longterm recovery of permanent cerebral ischemic damage and the neuroprotection of ginseng (Liu L. et al., 2019). The long-term pretreatment with ginsenoside reduced brain damage caused by middle cerebral artery occlusion (MCAO). Ginsenoside Rb1 


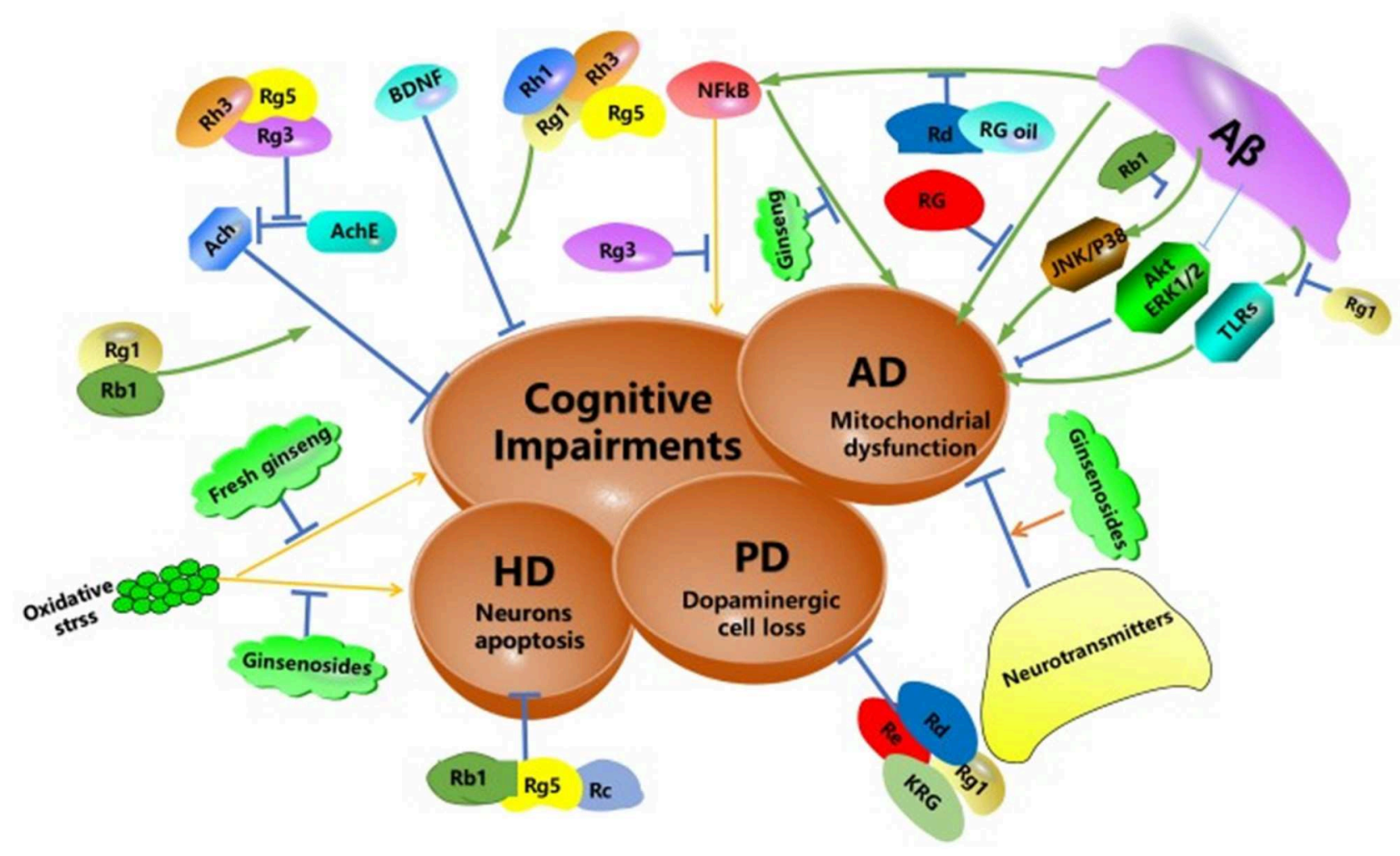

FIGURE 3 | Schematic diagram summarizing the potential protective effects of ginseng and its constituents against neurodegeneration. A $\beta$, amyloid beta peptide; TLRs, toll-like receptors; AD, Alzheimer's disease; HD, Huntington's disease; PD, Parkinson's disease; NF-кB, nuclear factor-kappa-light-chain-enhancer of an activated B cell; JNK, c-Jun N-terminal kinase, AChE, acetylcholinesterase; ERK, extracellular signal-regulated kinase; RG, red ginseng.

was beneficial for treating cerebral ischemia (Dong et al., 2017) and $\mathrm{Rb} 1$ protected blood-brain barrier (BBB) from ischemic stroke (Chen et al., 2015). Ginsenoside Rd protected against ischemic cerebral damage both in vitro and in vivo. Rd reduced the level of glutamate by increasing GLT-1 expression via ERK1/2 and PI3K/AKT pathways (Zhang et al., 2013). GAP-43, a neuron-specific protein, is related to regeneration and axonal outgrowth, Moreover, Rd could promote neurite outgrowth by upregulating GAP-43 expression mediated by PI3K/AKT and MAPK/ERK pathways, which is beneficial for treating ischemic stroke (Wu et al., 2016). Besides, Rd not only can activate PI3K/Akt and ERK1/2 signaling pathways but also can increase the expression of VEGF and BDNF in PC12 cells subjected OGD/reperfusion (Liu X. Y. et al., 2015). Ginsenoside Rg1 significantly reduced brain edema and infarct volume after MCAO by preventing of astrocytes from apoptosis (Sun et al., 2014). Ginseng total saponins (GTS) can protect brain cells, induce endogenous Neural stem cells to proliferate, and improve neurological function deficits after ischemic injury (Zheng et al., 2011). Compound K, a ginseng saponin metabolite, reduced the ischemic cerebral volume caused by MCAO and inhibited activation of microglia in the ischemic cortex (Park et al., 2012). In addition, Ginsenoside Rb1 reduced arterial vasospasm and brain edema and improved neurobehavioral function in the brain-injured rat (Li et al., 2011). All of these suggest that ginseng can protect the brain against ischemic stroke.

\section{The Role of Ginseng on Neurodegenerative Disorders}

Neurodegenerative disorders are multifactorial debilitating diseases and gradual loss of neuronal structure and function, like cognitive impairments, Alzheimer's disease (AD), Huntington's disease (HD), and Parkinson's disease (PD). Age and genetic mutations can also cause neurodegenerative diseases (Huang et al., 2019). Many pieces of research showed the active ingredients of ginseng improved neurodegenerative diseases by different pathways.

The decline of central cholinergic nerve function caused cognitive disorder. Ginsenoside Rg1 and Rb1 reversed the decline by increased the expression of acetylcholine(Ach), improving learning and memory (Lai et al., 2018). Ginsenoside Rg3-enriched ginseng extract alleviated scopolamine-induced memory damage through the inhibition of the NF- $\kappa$ B pathway and acetylcholinesterase (AchE) activity (Kim J. et al., 2016). Ginsenoside Rh3 and Rg5 may improve memory deficit induced by scopolamine in mice. They inhibited AChE activity and increased BDNF expression (Kim et al., 2013). Furthermore, Long-term administration of ginsenoside $\mathrm{Rg} 1$ and $\mathrm{Rh} 1$ can 
enhance learning ability by increasing BDNF (Hou et al., 2014; Zhu et al., 2015).

The deposition of the amyloid beta-peptide $(\mathrm{A} \beta)$ is associated with $\mathrm{AD}$. However, the mitochondrial deficiency was also considered a mediator or trigger for $\mathrm{AD}$ development. $\mathrm{RG}$ can reduce $A \beta$-induced mitochondrial dysfunction both in vitro and in vivo. The results showed RG may be a mitochondria-targeting agent for the treatment of AD (Shin et al., 2019). In addition, red ginseng oil decreased amyloid-beta peptide fragment 25$35\left(\mathrm{~A} \beta_{25-35}\right)$-induced neuronal inflammation and apoptosis by MAPK/NF-кB pathway (Lee et al., 2018b). A glycoprotein was extracted from ginseng, which named PGL-1. PGL-1 could alleviate the memory impairment of rats induced by $\mathrm{A} \beta_{25-35}$. The glycoproteins might be a promising anti-AD reagent (Luo et al., 2018). Ginsenoside Rb1 markedly decreased tau protein hyperphosphorylation through JNK/p38 MAPK pathway (Song et al., 2008). Ginsenoside Rd, as an alternative treatment for $\mathrm{AD}$ patients, could improve cognize ability in amyloid $\beta$-protein precursor (APP) transgenic(Tg) mice by inhibiting NF- $\kappa$ B (Liu J. et al., 2015). Ginsenoside Rg1 has anti-neurodegenerative effects on $\mathrm{A} \beta_{25-35}$ induced hippocampus and neurite damage in vitro. Activating Akt and ERK1/2 signaling may mediate enhanced neurite outgrowth and reduced $A \beta_{25-35}$ induced damage by Rg1 (Huang et al., 2016). In addition, toll-like receptors (TLRs), were an essential defense system for the mammalian host. In AD patients, cells express more TLRs than normal in the brain. Rg1 suppressed the signaling transduction pathway of TLR3 and TLR4 and decreased the inflammation factors (Zhao et al., 2014). Ginsenosides Rg1 can inhibit the signal transduction pathway of TLRs. Cognitive-related neurotransmitters disorders can be restored by ginsenosides (Zhang Y. et al., 2016). Moreover, ginseng extracts inhibited memory impairment of $\mathrm{AD}$ rats. The neuroprotective effects of Ginseng extracts may be related to the RAGE/NF-кB signal path (Tan et al., 2015). These findings suggest that ginseng can act on a variety of signaling pathways to improve the symptoms of Alzheimer's disease (Figure 3).

Degeneration of dopaminergic neurons was the main characteristic of PD. High levels of Carbon tetrachloride $\left(\mathrm{CCl}_{4}\right)$ affected the nervous system, including nigrostriatal dopaminergic nerve cells. Interestingly, ginsenosides $\mathrm{Rd}$ and Re reduced cell loss and degeneration (Zhang X. et al., 2016). In addition, Rd significantly attenuates SH-SY5Y cells injury in a PD model in vitro. The mechanism may be due to its mitochondrial function preservation and antioxidant effects (Liu Y. et al., 2015). Ginsenoside Rg1 decreased dopaminergic cell loss via $W n t / \beta$-catenin pathway (Zhou et al., 2016). And Rg1 inhibited inflammation-induced dopaminergic neuronal degeneration by glucocorticoid receptor signaling pathway (Sun et al., 2016). Korean Red Ginseng (KRG) also suppressed MPTPinduced behavioral dysfunction and dopaminergic neuronal death (Kim D. et al., 2016). Neuroinflammation caused by the

\section{REFERENCES}

Albert, P. R., Benkelfat, C., and Descarries, L. (2012). The neurobiology of depression-revisiting the serotonin hypothesis. I. Cellular and molecular microglial overactivation is associated with PD. Ginsenoside Rb1 inhibited lipopolysaccharide-induced microglial overactivation and protected dopaminergic neurons (Liu L. et al., 2019). Ginseng extract showed a partial therapeutic effect on the rat model of PD induced by the intrastriatal injection of rotenone (Khadrawy et al., 2016).

HD was a hereditary neurological disease caused by cytosine-adenine-guanine triplet expansion. HD patients exhibited abnormal body movements, personality disorders and cognitive impairments (Huang et al., 2019). Ginseng extract protopanaxatriol protects rat from oxidative stress induced by 3 nitropropionic (a model agent used to mimic the characteristics of HD) (Gao et al., 2015). Ginsenosides Rg5, Rb1, and Rc block glutamate-induced apoptosis of YAC128 medium spiny neurons (Wu et al., 2009). The potential protective effects of ginseng and its constituents against neurodegeneration were outlined in Figure 3.

\section{CONCLUSION}

Ginseng can be used as medicine and also be used as food. Due to the few side effects, consumers and researchers paid more attention to it (Kitts and $\mathrm{Hu}, 2000$ ). Over the years, ginseng had been increasingly studied in neurological diseases. Ginseng and its saponins were effective drugs for the treatment of brain diseases, like depression, neuronal damage, AD, PD, and HD. Ginseng can act on neurotransmitters (serotonin, acetylcholine), hormones (cortisol, corticosterone, testosterone) and receptor (androgen receptor, glucocorticoid receptor), brainderived neurotrophic factors, and a variety of intracellular signaling molecules. It is worth mentioning that Ginsenoside Rg1, as the main component of ginseng, possess plenteous biological activity, like anti-depression, anti-Alzheimer's disease, anti-Parkinson's disease and protect neurons. The antidepressant effect of Rg1 is the same as imipramine. So, Rg1 has great development potential. In summary, ginseng has a positive effect on the treatment of brain diseases and it deserves further research and development.

\section{AUTHOR CONTRIBUTIONS}

WH conceived the idea, wrote the manuscript, and edited the manuscript. YW and PZ participated in the discussion of the manuscript. RC revised the manuscript.

\section{FUNDING}

This work was supported by grants from the National Key Research and Development Program of China (2017YFC1702102), the Jilin Science \& Technology Development Plan (No. 20180101261JC). mechanisms. Philos. Trans. R. Soc. Lond. B Biol. Sci. 367, 2378-2381. doi: 10.1098/rstb.2012.0190

Aleksandrova, L. R., Wang, Y. T., and Phillips, A. G. (2019). Evaluation of the Wistar-Kyoto rat model of depression and the role of synaptic plasticity in 
depression and antidepressant response. Neurosci. Biobehav. Rev. 105, 1-23. doi: 10.1016/j.neubiorev.2019.07.007

Arborelius, L., Owens, M. J., Plotsky, P. M., and Nemeroff, C. B. (1999). The role of corticotropin-releasing factor in depression and anxiety disorders. J. Endocrinol. 160, 1-12. doi: 10.1677/joe.0.1600001

Bertrand, P. P., and Bertrand, R. L. (2010). Serotonin release and uptake in the gastrointestinal tract. Auton. Neurosci. 153, 47-57. doi: 10.1016/j.autneu.2009.08.002

Bocchio-Chiavetto, L., Bagnardi, V., Zanardini, R., Molteni, R., Nielsen, M. G., Placentino, A., et al. (2010). Serum and plasma BDNF levels in major depression: a replication study and meta-analyses. World J. Biol. Psychiatry 11, 763-773. doi: 10.3109/15622971003611319

Boonlert, W., Benya-Aphikul, H., Umka Welbat, J., and Rodsiri, R. (2017). Ginseng extract G115 attenuates ethanol-induced depression in mice by increasing brain BDNF levels. Nutrients 9:931. doi: 10.3390/nu9090931

Castren, E., and Rantamaki, T. (2010). The role of BDNF and its receptors in depression and antidepressant drug action: reactivation of developmental plasticity. Dev. Neurobiol. 70, 289-297. doi: 10.1002/dneu.20758

Chen, W., Guo, Y., Yang, W., Zheng, P., Zeng, J., and Tong, W. (2015). Protective effect of ginsenoside Rb1 on integrity of blood-brain barrier following cerebral ischemia. Exp. Brain Res. 233, 2823-2831. doi: 10.1007/s00221-015-4352-3

Chiba, S., Numakawa, T., Ninomiya, M., Richards, M. C., Wakabayashi, C., and Kunugi, H. (2012). Chronic restraint stress causes anxiety- and depression-like behaviors, downregulates glucocorticoid receptor expression, and attenuates glutamate release induced by brain-derived neurotrophic factor in the prefrontal cortex. Prog. Neuropsychopharmacol. Biol. Psychiatry 39, 112-119. doi: 10.1016/j.pnpbp.2012.05.018

Cho, I. H. (2012). Effects of Panax ginseng in neurodegenerative diseases. J. Ginseng Res. 36, 342-353. doi: 10.5142/jgr.2012.36.4.342

Choi, J. H., Lee, M. J., Jang, M., Kim, H. J., Lee, S., Lee, S. W., et al. (2018). Panax ginseng exerts antidepressant-like effects by suppressing neuroinflammatory response and upregulating nuclear factor erythroid 2 related factor 2 signaling in the amygdala. J. Ginseng Res. 42, 107-115. doi: 10.1016/j.jgr.2017.04.012

Dong, X., Zheng, L., Lu, S., and Yang, Y. (2017). Neuroprotective effects of pretreatment of ginsenoside R b1 on severe cerebral ischemia-induced injuries in aged mice: involvement of anti-oxidant signaling. Geriatr. Gerontol. Int. 17, 338-345. doi: 10.1111/ggi.12699

Dording, C. M., and Boyden, S. D. (2019). "Depression, antidepressants, and sexual functioning," in The Massachusetts General Hospital Guide to Depression, Current Clinical Psychiatry, eds B. G. Shapero D. Mischoulon, and C. Cusin (Cham: Humana Press), 123-137. doi: 10.1007/978-3-319-97241-1_9

Duman, R. S., Aghajanian, G. K., Sanacora, G., and Krystal, J. H. (2016). Synaptic plasticity and depression: new insights from stress and rapid-acting antidepressants. Nat. Med. 22, 238-249. doi: 10.1038/nm.4050

Farber, G. A., and Goldberg, J. F. (2004). Regarding combining norepinephrine and serotonin reuptake inhibition mechanisms for treatment of depression: a double-blind randomized study: optimizing initial interventions. Biol. Psychiatry 56, 535-536. doi: 10.1016/j.biopsych.2004.07.013

Gao, Y., Chu, S. F., Li, J. P., Zhang, Z., Yan, J. Q., Wen, Z. L., et al. (2015). Protopanaxtriol protects against 3-nitropropionic acid-induced oxidative stress in a rat model of Huntington's disease. Acta Pharmacol. Sin. 36, 311-322. doi: 10.1038/aps.2014.107

Gillman, P. K. (2007). Tricyclic antidepressant pharmacology and therapeutic drug interactions updated. Br. J. Pharmacol. 151, 737-748. doi: 10.1038/sj.bjp.0707253

Haenisch, B., and Bonisch, H. (2011). Depression and antidepressants: insights from knockout of dopamine, serotonin or noradrenaline re-uptake transporters. Pharmacol. Ther. 129, 352-368. doi: 10.1016/j.pharmthera.2010.12.002

Hou, J., Xue, J., Lee, M., Yu, J., and Sung, C. (2014). Long-term administration of ginsenoside Rhl enhances learning and memory by promoting cell survival in the mouse hippocampus. Int. J. Mol. Med. 33, 234-240. doi: 10.3892/ijmm.2013.1552

Hou, J., Xue, J., Wang, Z., and Li, W. (2018). Ginsenoside Rg3 and Rh2 protect trimethyltin-induced neurotoxicity via prevention on neuronal apoptosis and neuroinflammation. Phytother. Res. 32, 2531-2540. doi: 10.1002/ptr.6193

Huang, L., Liu, L.-F., Liu, J., Dou, L., Wang, G.-Y., Liu, X.-Q., et al. (2016). Ginsenoside Rg1 protects against neurodegeneration by inducing neurite outgrowth in cultured hippocampal neurons. Neural Regen. Res. 11, 319-325. doi: 10.4103/1673-5374.177741

Huang, X., Li, N., Pu, Y., Zhang, T., and Wang, B. (2019). Neuroprotective effects of ginseng phytochemicals: recent perspectives. Molecules 24:2939. doi: 10.3390/molecules24162939

Iqbal, H., Kim, S.-K., Cha, K.-M., Jeong, M.-S., Ghosh, P., and Rhee, D.-K. (2019). Korean Red Ginseng alleviates neuroinflammation and promotes cell survival in the intermittent heat stress-induced rat brain by suppressing oxidative stress via estrogen receptor beta and brain-derived neurotrophic factor upregulation. J. Ginseng Res. doi: 10.1016/j.jgr.2019.05.007

Jang, D., Lee, H.-J., Lee, K., Kim, K.-R., Won, R., Lee, S. E., et al. (2019). White ginseng ameliorates depressive behavior and increases hippocampal 5 HT level in the stressed ovariectomized rats. Biomed. Res. Int. 2019:5705232. doi: 10.1155/2019/5705232

Jiang, B., Xiong, Z., Yang, J., Wang, W., Wang, Y., Hu, Z. L., et al. (2012). Antidepressant-like effects of ginsenoside $\operatorname{Rg} 1$ are due to activation of the BDNF signalling pathway and neurogenesis in the hippocampus. Br. J. Pharmacol. 166, 1872-1887. doi: 10.1111/j.1476-5381.2012.01902.x

Jiang, N., Zhang, B. Y., Dong, L. M., Lv, J. W., Lu, C., Wang, Q., et al. (2018). Antidepressant effects of dammarane sapogenins in chronic unpredictable mild stress-induced depressive mice. Phytother. Res. 32, 1023-1029. doi: 10.1002/ptr.6040

Jin, Y., Cui, R., Zhao, L., Fan, J., and Li, B. (2019). Mechanisms of Panax ginseng action as an antidepressant. Cell Prolif. 52:e12696. doi: 10.1111/cpr.12696

Kanayama, G., Amiaz, R., Seidman, S., and Pope, H. G. Jr. (2007). Testosterone supplementation for depressed men: current research and suggested treatment guidelines. Exp. Clin. Psychopharmacol. 15, 529-538. doi: 10.1037/1064-1297.15.6.529

Kawabata, K., Kawai, Y., and Terao, J. (2010). Suppressive effect of quercetin on acute stress-induced hypothalamic-pituitary-adrenal axis response in Wistar rats. J. Nutr. Biochem. 21, 374-380. doi: 10.1016/j.jnutbio.2009.01.008

Khadrawy, Y. A., Mourad, I. M., Mohammed, H. S., Noor, N. A., and Ezz, H. S. A. (2016). A study on the possible therapeutic role of Panax ginseng extract against a rat model of Parkinson's disease induced by intrastriatal rotenone injection. Int. J. Clin. Exp. Med. 9, 3831-3841.

Kim, D., Jeon, H., Ryu, S., Koo, S., Ha, K. T., and Kim, S. (2016). Proteomic analysis of the effect of korean red ginseng in the striatum of a Parkinson's disease mouse model. PLoS ONE 11:e0164906. doi: 10.1371/journal.pone.0164906

Kim, D. H., Kim, D. W., Jung, B. H., Lee, J. H., Lee, H., Hwang, G. S., et al. (2019). Ginsenoside Rb2 suppresses the glutamate-mediated oxidative stress and neuronal cell death in HT22 cells. J. Ginseng Res. 43, 326-334. doi: 10.1016/j.jgr.2018.12.002

Kim, E. J., Jung, I. H., van Le, T. K., Jeong, J. J., Kim, N. J., and Kim, D. H. (2013). Ginsenosides Rg5 and Rh3 protect scopolamine-induced memory deficits in mice. J. Ethnopharmacol. 146, 294-299. doi: 10.1016/j.jep.2012.12.047

Kim, H. J., Park, S. D., Lee, R. M., Lee, B. H., Choi, S. H., Hwang, S. H., et al. (2017). Gintonin attenuates depressive-like behaviors associated with alcohol withdrawal in mice. J. Affect. Disord. 215, 23-29. doi: 10.1016/j.jad.2017.03.026

Kim, J., Shim, J., Lee, S., Cho, W.-H., Hong, E., Lee, J. H., et al. (2016). Rg3enriched ginseng extract ameliorates scopolamine-induced learning deficits in mice. BMC Complement. Altern. Med. 16:66. doi: 10.1186/s12906-016-1050-z

Kim, S. O., You, J. M., Yun, S. J., Son, M. S., Nam, K. N., Hong, J. W., et al. (2010). Ginsenoside rb1 and rg3 attenuate glucocorticoid-induced neurotoxicity. Cell. Mol. Neurobiol. 30, 857-862. doi: 10.1007/s10571-010-9513-0

Kitts, D., and Hu, C. (2000). Efficacy and safety of ginseng. Public Health Nutr. 3, 473-485. doi: 10.1017/S1368980000000550

Krishnan, V., and Nestler, E. J. (2008). The molecular neurobiology of depression. Nature 455, 894-902. doi: 10.1038/nature07455

Lai, M., Zhang, H. -J., Wang, F., Shao, Y. I., Yang, M.-W., Hong, F. F., et al. (2018). Anti-aging effects of ginseng and ginsenosides on the nervous system. Int. J. Pharmacol. 14, 1188-1197. doi: 10.3923/ijp.2018.1188.1197

Lee, K. J., and Ji, G. E. (2014). The effect of fermented red ginseng on depression is mediated by lipids. Nutr. Neurosci. 17, 7-15. doi: 10.1179/1476830513Y.0000000059

Lee, S., Lee, S. O., Kim, G. L., and Rhee, D. K. (2018a). Estrogen receptor-beta of microglia underlies sexual differentiation of neuronal protection via ginsenosides in mice brain. CNS Neurosci. Ther. 24, 930-939. doi: $10.1111 /$ cns. 12842 
Lee, S., and Rhee, D. K. (2017). Effects of ginseng on stress-related depression, anxiety, and the hypothalamic-pituitary-adrenal axis. J. Ginseng Res. 41, 589-594. doi: 10.1016/j.jgr.2017.01.010

Lee, S., Youn, K., and Jun, M. (2018b). Major compounds of red ginseng oil attenuate $A \beta$ 25-35-induced neuronal apoptosis and inflammation by modulating MAPK/NF-кB pathway. Food Funct. 9, 4122-4134. doi: $10.1039 / \mathrm{C} 8 \mathrm{FO} 00795 \mathrm{~K}$

Li, D. W., Zhou, F. Z., Sun, X. C., Li, S. C., Yang, J. B., Sun, H. H., et al. (2019). Ginsenoside Rb1 protects dopaminergic neurons from inflammatory injury induced by intranigral lipopolysaccharide injection. Neural. Regen. Res. 14, 1814-1822. doi: 10.4103/1673-5374.257536

Li, Y., Tang, J., Khatibi, N. H., Zhu, M., Chen, D., Tu, L., et al. (2011). Treatment with ginsenoside rb1, a component of Panax ginseng, provides neuroprotection in rats subjected to subarachnoid hemorrhage-induced brain injury. Acta Neurochir. Suppl. 110 (Pt 2), 75-79. doi: 10.1007/978-3-7091-0356-2_14

Liu, J., Yan, X., Li, L., Li, Y., Zhou, L., Zhang, X., et al. (2015). Ginsenoside Rd improves learning and memory ability in APP transgenic mice. J. Mol. Neurosci. 57, 522-528. doi: 10.1007/s12031-015-0632-4

Liu, L., Kelly, M. G., Wierzbicki, E. L., Escober-Nario, I. C., Vollmer, M. K., and Dore, S. (2019). Nrf2 plays an essential role in long-term brain damage and neuroprotection of Korean red Ginseng in a permanent cerebral ischemia model. Antioxidants 8:273. doi: 10.3390/antiox8080273

Liu, M., Liu, J., Zhang, L., Geng, Q., and Ge, Y. (2019). Antidepressant-like effects of ginseng fruit saponin in myocardial infarction mice. Biomed. Pharmacother. 115:108900. doi: 10.1016/j.biopha.2019.108900

Liu, X. Y., Zhou, X. Y., Hou, J. C., Zhu, H., Wang, Z., Liu, J. X., et al. (2015). Ginsenoside Rd promotes neurogenesis in rat brain after transient focal cerebral ischemia via activation of PI3K/Akt pathway. Acta Pharmacol. Sin. 36, 421-428. doi: 10.1038/aps.2014.156

Liu, Y., Zhang, R. Y., Zhao, J., Dong, Z., Feng, D. Y., Wu, R., et al. (2015). Ginsenoside Rd protects SH-SY5Y cells against 1-Methyl-4-phenylpyridinium induced injury. Int. J. Mol. Sci. 16, 14395-14408. doi: 10.3390/ijms160714395

Luo, H., Hu, J., Wang, Y., Chen, Y., Zhu, D., Jiang, R., et al. (2018). In vivo and in vitro neuroprotective effects of Panax ginseng glycoproteins. Int. J. Biol. Macromol. 113, 607-615. doi: 10.1016/j.ijbiomac.2018.02.015

Majid, A. (2019). Panax ginseng-a review. Univ. Thi-Qar J. Sci. 7, 96-102.

McEwen, B. S. (2008). Central effects of stress hormones in health and disease: understanding the protective and damaging effects of stress and stress mediators. Eur. J. Pharmacol. 583, 174-185. doi: 10.1016/j.ejphar.2007.11.071

McLean, P. G., Borman, R. A., and Lee, K. (2007). 5-HT in the enteric nervous system: gut function and neuropharmacology. Trends Neurosci. 30, 9-13. doi: 10.1016/j.tins.2006.11.002

Molteni, R., Calabrese, F., Bedogni, F., Tongiorgi, E., Fumagalli, F., Racagni, G., et al. (2006). Chronic treatment with fluoxetine up-regulates cellular BDNF mRNA expression in rat dopaminergic regions. Int. J. Neuropsychopharmacol. 9, 307-317. doi: 10.1017/S1461145705005766

Mou, Z., Huang, Q., Chu, S. F., Zhang, M. J., Hu, J. F., Chen, N. H., et al. (2017). Antidepressive effects of ginsenoside Rg1 via regulation of HPA and HPG axis. Biomed. Pharmacother. 92, 962-971. doi: 10.1016/j.biopha.2017.05.119

Ong, W. Y., Farooqui, T., Koh, H. L., Farooqui, A. A., and Ling, E. A. (2015). Protective effects of ginseng on neurological disorders. Front. Aging Neurosci. 7:129. doi: 10.3389/fnagi.2015.00129

Park, J.-S., Shin, J. A., Jung, J.-S., Hyun, J.-W., van Le, T. K., Kim, D.-H., et al. (2012). Anti-inflammatory mechanism of compound $\mathrm{K}$ in activated microglia and its neuroprotective effect on experimental stroke in mice. J. Pharmacol. Exp. Ther. 341, 59-67. doi: 10.1124/jpet.111.189035

Rajabian, A., Rameshrad, M., and Hosseinzadeh, H. (2019). Therapeutic potential of Panax ginseng and its constituents, ginsenosides and gintonin, in neurological and neurodegenerative disorders: a patent review. Expert Opin. Ther. Pat. 29, 55-72. doi: 10.1080/13543776.2019.1556258

Reus, G. Z., Dos Santos, M. A., Abelaira, H. M., Ribeiro, K. F., Petronilho, F., Vuolo, F., et al. (2013). Imipramine reverses alterations in cytokines and BDNF levels induced by maternal deprivation in adult rats. Behav. Brain Res. 242, 40-46. doi: 10.1016/j.bbr.2012.11.044

Saldanha, D., Kumar, N., Ryali, V., Srivastava, K., and Pawar, A. A. (2009). Serum serotonin abnormality in depression. Med. J. Armed Forces India 65, 108-112. doi: 10.1016/S0377-1237(09)80120-2
Sapolsky, R. M., Romero, L. M., and Munck, A. U. (2000). How do glucocorticoids influence stress responses? Integrating permissive, suppressive, stimulatory, and preparative actions. Endocr. Rev. 21, 55-89. doi: 10.1210/er.21.1.55

Sekiyama, T., Nakatani, Y., Yu, X., Seki, Y., Sato-Suzuki, I., and Arita, H. (2013). Increased blood serotonin concentrations are correlated with reduced tension/anxiety in healthy postpartum lactating women. Psychiatry Res. 209, 560-565. doi: 10.1016/j.psychres.2013.03.009

Shahrajabian, M. H., Sun, W., and Cheng, Q. (2019). A review of Ginseng species in different regions as a multipurpose herb in traditional Chinese medicine, modern herbology and pharmacological science. J. Med. Plant Res. 13, 213-226. doi: 10.5897/JMPR2019.6731

Shapero, B. G., Curley, E. E., Black, C. L., and Alloy, L. B. (2019). The interactive association of proximal life stress and cumulative HPA axis functioning with depressive symptoms. Depress. Anxiety 36, 1089-1101. doi: 10.1002/da.22957

Shin, S. J., Jeon, S. G., Kim, J. I., Jeong, Y. O., Kim, S., Park, Y. H., et al. (2019). Red ginseng attenuates abeta-induced mitochondrial dysfunction and abetamediated pathology in an animal model of Alzheimer's Disease. Int. J. Mol. Sci. 20:3030. doi: 10.3390/ijms 20123030

Smith, K. (2014). Mental health: a world of depression. Nature 515:181. doi: $10.1038 / 515180$ a

Song, J., Chen, X., Zhang, J., Huang, T., Zeng, Y., Shen, J., et al. (2008). JNK/p38 MAPK involves in ginsenoside Rb1 attenuating beta-amyloid peptide (25-35)induced tau protein hyperphosphorylation in embryo rat cortical neurons. Yao xиe xue bao 43, 29-34. doi: 10.3321/j.issn:0513-4870.2008.01.005

Sun, C., Lai, X., Huang, X., and Zeng, Y. (2014). Protective effects of ginsenoside Rg1 on astrocytes and cerebral ischemic-reperfusion mice. Biol. Pharm. Bull. 37, 1891-1898. doi: 10.1248/bpb.b14-00394

Sun, X. C., Ren, X. F., Chen, L., Gao, X. Q., Xie, J. X., and Chen, W. F. (2016). Glucocorticoid receptor is involved in the neuroprotective effect of ginsenoside $\mathrm{Rg} 1$ against inflammation-induced dopaminergic neuronal degeneration in substantia nigra. J. Steroid Biochem. Mol. Biol. 155(Pt A), 94-103. doi: 10.1016/j.jsbmb.2015.09.040

Tan, X., Gu, J., Zhao, B., Wang, S., Yuan, J., Wang, C., et al. (2015). Ginseng improves cognitive deficit via the RAGE/NF- $\mathrm{KB}$ pathway in advanced glycation end product-induced rats. J. Ginseng Res. 39, 116-124. doi: 10.1016/j.jgr.2014.09.002

Wang, G. L., He, Z. M., Zhu, H. Y., Gao, Y. G., Zhao, Y., Yang, H., et al. (2017). Involvement of serotonergic, noradrenergic and dopaminergic systems in the antidepressant-like effect of ginsenoside $\mathrm{Rb} 1$, a major active ingredient of Panax ginseng C.A. Meyer. J. Ethnopharmacol. 204, 118-124. doi: 10.1016/j.jep.2017.04.009

Wang, W., Liu, X., Liu, J., Cai, E., Zhao, Y., Li, H., et al. (2018). Sesquiterpenoids from the root of Panax ginseng attenuates lipopolysaccharide-induced depressive-like behavior through the brain-derived neurotrophic factor/tropomyosin-related kinase $B$ and sirtuin Type 1/nuclear factor-kappaB signaling pathways. J. Agric. Food Chem. 66, 265-271. doi: $10.1021 /$ acs.jafc.7b04835

Wu, J., Jeong, H. K., Bulin, S. E., Kwon, S. W., Park, J. H., and Bezprozvanny, I. (2009). Ginsenosides protect striatal neurons in a cellular model of Huntington's disease. J. Neurosci. Res. 87, 1904-1912. doi: 10.1002/jnr.22017

Wu, S.-D., Xia, F., Lin, X.-M., Duan, K.-L., Wang, F., Lu, Q.-L., et al. (2016). Ginsenoside-Rd promotes neurite outgrowth of PC12 cells through MAPK/ERK-and PI3K/AKT-dependent pathways. Int. J. Mol. Sci. 17:177. doi: 10.3390/ijms17020177

Xu, D., Wang, C., Zhao, W., Gao, S., and Cui, Z. (2017). Antidepressant-like effects of ginsenoside Rg5 in mice: Involving of hippocampus BDNF signaling pathway. Neurosci. Lett. 645, 97-105. doi: 10.1016/j.neulet.2017.02.071

Xu, T. Z., Shen, X. Y., Sun, L. L., Chen, Y. L., Zhang, B. Q., Huang, D. K., et al. (2019). Ginsenoside Rg1 protects against H2O2induced neuronal damage due to inhibition of the NLRP1 inflammasome signalling pathway in hippocampal neurons in vitro. Int. J. Mol. Med. 43, 717-726. doi: 10.3892/ijmm.2018.4005

Yamada, N., Araki, H., and Yoshimura, H. (2011). Identification of antidepressantlike ingredients in ginseng root (Panax ginseng C.A. Meyer) using a menopausal depressive-like state in female mice: participation of 5-HT2A receptors. Psychopharmacology 216, 589-599. doi: 10.1007/s00213-011-2252-1

You, Z., Yao, Q., Shen, J., Gu, Z., Xu, H., Wu, Z., et al. (2017). Antidepressantlike effects of ginsenoside $\operatorname{Rg} 3$ in mice via activation of the hippocampal 
BDNF signaling cascade. J. Nat. Med. 71, 367-379. doi: 10.1007/s11418-0161066-1

Zahn, D., Petrak, F., Franke, L., Hagele, A. K., Juckel, G., Lederbogen, F., et al. (2015). Cortisol, platelet serotonin content, and platelet activity in patients with major depression and type 2 diabetes: an exploratory investigation. Psychosom. Med. 77, 145-155. doi: 10.1097/PSY.0000000000000145

Zhang, X., Shi, M., Bjoras, M., Wang, W., Zhang, G., Han, J., et al. (2013). Ginsenoside Rd promotes glutamate clearance by up-regulating glial glutamate transporter GLT-1 via PI3K/AKT and ERK1/2 pathways. Front. Pharmacol. 4:152. doi: 10.3389/fphar.2013.00152

Zhang, X., Wang, Y., Ma, C., Yan, Y., Yang, Y., Wang, X., et al. (2016). Ginsenoside $\mathrm{Rd}$ and ginsenoside Re offer neuroprotection in a novel model of Parkinson's disease. Am. J. Neurodegener. Dis. 5, 52-61.

Zhang, Y., Pi, Z., Song, F., and Liu, Z. (2016). Ginsenosides attenuate d-galactoseand $\mathrm{AlCl} 3$-inducedspatial memory impairment by restoring the dysfunction of the neurotransmitter systems in the rat model of Alzheimer's disease. J. Ethnopharmacol. 194, 188-195. doi: 10.1016/j.jep.2016.09.007

Zhang, Z., Deng, T., Wu, M., Zhu, A., and Zhu, G. (2019). Botanicals as modulators of depression and mechanisms involved. Chin. Med. 14:24. doi: 10.1186/s13020-019-0246-9

Zhao, B. S., Liu, Y., Gao, X. Y., Zhai, H. Q., Guo, J. Y., and Wang, X. Y. (2014). Effects of ginsenoside $\mathrm{Rg} 1$ on the expression of toll-like receptor 3, 4 and their signalling transduction factors in the NG108-15 murine neuroglial cell line. Molecules 19, 16925-16936. doi: 10.3390/molecules191016925
Zheng, G. Q., Cheng, W., Wang, Y., Wang, X. M., Zhao, S. Z., Zhou, Y., et al. (2011). Ginseng total saponins enhance neurogenesis after focal cerebral ischemia. J. Ethnopharmacol. 133, 724-728. doi: 10.1016/j.jep.2010.01.064

Zhou, T., Zu, G., Zhang, X., Wang, X., Li, S., Gong, X., et al. (2016). Neuroprotective effects of ginsenoside Rg1 through the Wnt/beta-catenin signaling pathway in both in vivo and in vitro models of Parkinson's disease. Neuropharmacology 101, 480-489. doi: 10.1016/j.neuropharm.2015. 10.024

Zhu, G., Wang, Y., Li, J., and Wang, J. (2015). Chronic treatment with ginsenoside Rg1 promotes memory and hippocampal long-term potentiation in middleaged mice. Neuroscience 292, 81-89. doi: 10.1016/j.neuroscience.2015. 02.031

Conflict of Interest: The authors declare that the research was conducted in the absence of any commercial or financial relationships that could be construed as a potential conflict of interest.

Copyright (c) $2020 \mathrm{Hou}$, Wang, Zheng and Cui. This is an open-access article distributed under the terms of the Creative Commons Attribution License (CC BY). The use, distribution or reproduction in other forums is permitted, provided the original author(s) and the copyright owner(s) are credited and that the original publication in this journal is cited, in accordance with accepted academic practice. No use, distribution or reproduction is permitted which does not comply with these terms. 